\title{
Control of breathing in mechanically ventilated patients
}

\author{
D. Georgopoulos, C. Roussos
}

\begin{abstract}
Control of breathing in mechanically ventilated patients. D. Georgopoulos, C. Roussos. (C) ERS Journals Ltd 1996.

ABSTRACT: During mechanical ventilation, the respiratory system is under the influence of two pumps, the ventilator pump and the patient's own respiratory muscles. Depending on the mode of mechanical ventilatory support, ventilation may be totally controlled by the ventilator or may be determined by the interaction between patient respiratory effort and ventilator function. In either case, compared to spontaneous breathing, the breathing pattern is altered and this may influence: 1) force-length and force-velocity relationships of respiratory muscles (mechanical feedback); 2) chemical stimuli (chemical feedback); 3) the activity of various receptors located in the respiratory tract, lung and chest wall (reflex feedback); and 4) behavioural response (behavioural feedback). Changes in these feedback systems may modify the function of the ventilator, in a way that is dependent on the mode of mechanical ventilatory support, ventilator settings, mechanics of the respiratory system and the sleep/awake stage.

Thus, the response of ventilator to patient effort, and that of patient effort to ventilator-delivered breath are inevitably the two components of control of breathing during mechanical ventilation; the ventilatory output is the final expression of the interaction between these two components. As a result of this interaction, the various aspects of control of breathing of the respiratory system may be masked or modulated by mechanical ventilation, depending on several factors related both to patient and ventilator. This should be taken into consideration in the management of mechanically ventilated patients.

Eur Respir J., 1996, 9, 2151-2160.
\end{abstract}

Pulmonary and Critical Care Dept, General Hospital "G. Papanicolaou", University of Thessaloniki, Thessaloniki, Greece and Critical Care Dept, "Evangelismos" Hospital, University of Athens, Athens, Greece.

Correspondence: D. Georgopoulos General Hospital "G. Papanicolaou" Pulmonary Dept

Respiratory Failure Unit

Exochi 57010

Thessaloniki

Greece

Keywords: Behavioural feedback chemical feedback

mechanical feedback

mechanical ventilation

reflex feedback

Received: May 201996

Accepted after revision July 71996
The act of breathing is a complex process $[1,2]$. Briefly, the medullary respiratory controller (central controller) accepts information from chemical (peripheral and central chemoreceptors) and nonchemical sources. Based on this information, the central controller activates spinal motor neurons serving respiratory muscles, with an intensity and rate that may vary substantially between breaths. The activity of spinal motor neurons is conveyed to respiratory muscles, which contract and generate pressure (Pmus). Pmus is dissipated to overcome the resistance and elastance of the respiratory system (inertia is negligible) and this combination determines the volume-time profile and, depending on breath timing, ventilation. Volumetime profile and breath timing via force-length and forcevelocity relationships of respiratory muscles affect $P$ mus, whereas they modify the activity of spinal motor neurons and the medullary respiratory controller via afferent nerves from various receptors. On the other hand, ventilation and gas exchange properties of the lung determine arterial blood gas values, which in turn, via peripheral and central chemoreceptors, affect the activity of the medullary respiratory controller, closing the loop.

In a mechanically-ventilated patient, the breath delivered by the ventilator has two components, one related to the volume-time profile and the other to ventilator timing $[3,4]$. Volume-time profile, according to the equation of motion [5], is determined by the combined action of $P$ mus, pressure provided by the ventilator $(P$ aw $)$ and the mechanical properties of the respiratory system (elastance and resistance) (fig. 1). Depending on the mode of mechanical ventilatory support, volume-time profile and ventilator timing may be totally controlled by the

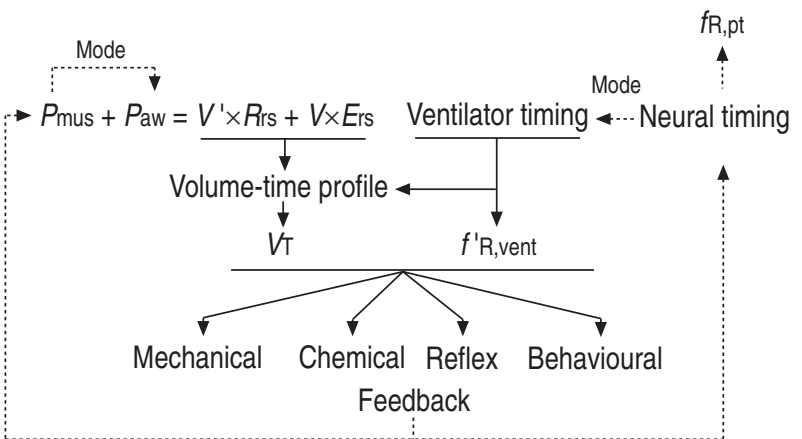

Fig. 1. - Schematic representation of the interaction between patient respiratory effort and ventilator-delivered breath. Pmus: pressure generated by respiratory muscles (inspiratory muscles generate positive pressure and expiratory muscles negative); $P$ aw: airway pressure; $V$ : instantaneous volume above passive functional residual capacity (FRC); $V^{\prime}$ : instantaneous flow (inspiratory flow is positive); $R$ rs: resistance of the respiratory system; Ers: elastance of the respiratory system; Ventilator timing: duration of inspiratory and expiratory flow (mechanical inspiratory and expiratory time); Neural timing: neural (patient) inspiratory and expiratory time; $V \mathrm{~T}$ : tidal volume. $f$ Rvent: ventilator (respirator) frequency; $f$ R,pt: patient spontaneous breathing frequency. Depending on the mode of ventilatory support, $P$ mus and neural timing may or may not affect $P$ aw and ventilator timing, respectively. Note that $f \mathrm{R}$,vent may not reflect $f$ R,pt. See text for further details. 
ventilator or may be determined by the interaction between patient respiratory effort and ventilator function [3, 4]. In either case, compared to spontaneous breathing, the pattern of breathing and ventilation are changed. These changes may alter: 1) force-length and force-velocity relationships of respiratory muscles (mechanical feedback) $[6,7]$; 2) chemical stimuli (chemical feedback) [8]; and 3) the activity of various receptors located in the respiratory tract, lung and chest wall (reflex feedback) $[9,10]$. Furthermore, changes in volume-time profile and breathing pattern are readily perceived in awake subjects and may evoke behavioural ventilatory responses (behavioural feedback) [11, 12]. As a result of mechanical, chemical, reflex and behavioural feedback, $P$ mus and patient neural timing (neural inspiratory and expiratory duration) are altered and these alterations, depending on the mode of mechanical ventilatory support $[3,4]$, may or may not influence $P$ aw and ventilator timing (fig. 1). Thus, the ventilatory output is the final expression of the interaction between patient effort and ventilator. It follows that the response of ventilator to patient effort, and that of patient effort to ventilatordelivered breath are inevitably the two components that control breathing during mechanical ventilation. An understanding of these two components is essential for the physician dealing with the issue of control of breathing in mechanically-ventilated patients.

\section{Response of ventilator to patient effort}

\section{Basic principles of positive pressure ventilators}

Positive pressure ventilators can be characterized by various variables, which control the initiation of the mechanical breath, gas delivery and mechanical inspiratory time [3]. The response of the ventilator to patient effort depends on the type of variables that a specific mode of ventilatory support uses.

Trigger variable. The trigger variable defines when the ventilator initiates gas delivery. This variable may be time, pressure or flow $[3,13]$. With time-triggering, the ventilator delivers gas at fixed time intervals. With pressure- or flow-triggering, gas delivery is initiated when the patient decreases airway pressure $(P$ aw $)$ below positive end-expiratory pressure (PEEP) before the assist ventilation begins. In some modes, the ventilator does not provide any flow until $P$ aw decreases to a predetermined level (pressure-triggering); whilst in other modes, the ventilator allows air to flow in response to the decrease in $P$ aw, and triggering occurs when flow from machine to patient exceeds a set level (flow-triggering). Therefore, with time-triggering, the ventilator rate bears no relationship to patient breathing frequency; while with pressure- or flow-triggering, the ventilator rate is, theoretically, set by the patient.

Variables that control gas delivery and mechanical inspiratory time. Gas delivery from the ventilator may be governed by a set flow (volume-control), a set pressure (pressure-control), or instantaneous flow and volume (proportional assist ventilation) [3, 4]. With volume-control modes, the volume-time profile and duration of inspiratory flow are predetermined by the ventilator settings. Thus, changes in $P$ mus and neural inspiratory time cannot modify tidal volume $(V \mathrm{~T})$ delivered by the ventilator. Any change in $P$ mus causes $P$ aw to change in the opposite direction, because total pressure $(P$ aw $+P$ mus $)$ is not changed. Therefore, with volume-control modes, the ventilator antagonizes the intensity of patient effort (fig. 1). Furthermore, the time at which inspiratory flow is terminated is independent of neural inspiratory duration. It follows that, with volume-control neither the intensity of patient effort nor neural inspiratory time are expressed by the output of the ventilator.

With pressure-control, the ventilator once triggered causes $P$ aw to increase rapidly to a preset level, remaining at that level until a preset cycling-off criterion (the variable that terminates gas delivery) is reached $[3,4,14]$. Because $P$ aw is constant, the volume-time profile is under the influence of $P$ mus, and any change in the intensity of patient effort is expressed by a change in inspiratory flow rate (fig. 1). The cycling-off criterion may be a set time or flow. With time-cycling, neural inspiratory time is ignored by the ventilator and the tidal volume is determined by $P$ mus waveform (inspiratory and expiratory) and mechanical properties of the respiratory system [5] (fig. 1). With flow-cycling, gas delivery is terminated when inspiratory flow reaches a fixed level (usually 0.1 $\mathrm{L} \cdot \mathrm{s}^{-1}$ ) or a value which is proportional to peak inspiratory flow (usually 25\%). This method is called pressuresupport (PS) and is widely-used [3, 14]. Theoretically, with PS the patient retains considerable control of the inspiratory volume-time profile and inspiratory flow duration; any change in the intensity and rate of patient effort should be expressed by $V$ T and ventilator timing. Nevertheless, in the face of high ventilatory demands, many ventilators are not able to maintain constant $P$ aw, and $P$ aw deviates from the target level [15]. Furthermore, it has been shown on theoretical grounds that the ability to modulate $V$ T during PS is limited, particularly in patients with abnormal mechanics, for reasons related both to patient and ventilator (for review see [15]). Therefore, the ventilatory consequences of a given increase in patient effort might be expressed inappropriately (see below).

Proportional assist ventilation (PAV) is a new mode of mechanical ventilation in which $P$ aw is proportional to instantaneous flow and volume $[4,16]$. Thus, there is not a target level either for pressure or for flow. The proportionality between $P$ aw and instantaneous flow and volume is preset by the ventilator, according to the following equation:

$$
P \text { aw }=\mathrm{k}_{1} \times V^{\prime}+\mathrm{k}_{2} \times V
$$

where $V^{\prime}$ and $V$ are instantaneous flow and volume, respectively, and $\mathrm{k}_{1}$ and $\mathrm{k}_{2}$ are gain factors. To the extent that $V^{\prime}$ and $V$ depend on the intensity of inspiratory effort ( $P$ mus), $P$ aw is positively related to $P$ mus, as opposed to being negatively related (volume control) or independent (pressure control). With PAV, the volume-time profile and breathing pattern are tightly linked to $P$ mus waveform $[4,15,16]$. Any change in the rate and intensity of patient effort should be expressed by ventilatory output. 


\section{Missing effort}

Ideally, in patients ventilated on assisted modes, all inspiratory efforts trigger the ventilator, which delivers gas and supports the patient effort [3]. The level of support may range from zero to near maximum and, depending on the mode used, may vary from breath to breath [3]. With zero support, the patient performs the total work of breathing; whilst with near maximum support, inspiratory muscles relax after triggering.

High resistance to airflow, low elastic recoil, high ventilatory demands, and short expiratory time may not permit the system to reach static equilibrium volume at the end of expiration [17]. Hence, inspiration begins at volumes at which the respiratory system exhibits a positive recoil pressure, referred to as intrinsic PEEP (PEEPi) [18-22]. This phenomenon is called dynamic hyperinflation and is a common finding in mechanically-ventilated patients [18-21]. In this case, the patients must first generate enough $P$ mus to overcome PEEPi before triggering occurs. There might be a situation where pressure generated by the inspiratory muscles to initiate a breath is less than PEEPi plus the airway pressure decrease required to trigger the ventilator, and, therefore, inspiratory effort fails to trigger the ventilator ("missing effort") [15, 23-26]. Because there is no inflation during this breath, lung volume continues to decline, so that the elastic recoil is less at the beginning of the next patient effort and the patient is in a better position to trigger the ventilator on the next spontaneous cycle.

Figure 2 shows airway pressure $(P$ aw $)$, airflow, and oesophageal pressure $\left(P_{\text {oes }}\right)$ in a patient with chronic obstructive pulmonary disease (COPD) mechanicallyventilated on assist volume-controlled (AVC) mode. In the example presented in figure $2, V \mathrm{~T}$ was set to $0.55 \mathrm{~L}$, given with a square-wave flow-time profile. On one occasion, inspiratory flow $\left(V^{\prime} \mathrm{I}\right)$ was set to $90 \mathrm{~L} \cdot \mathrm{min}^{-1}$

a)

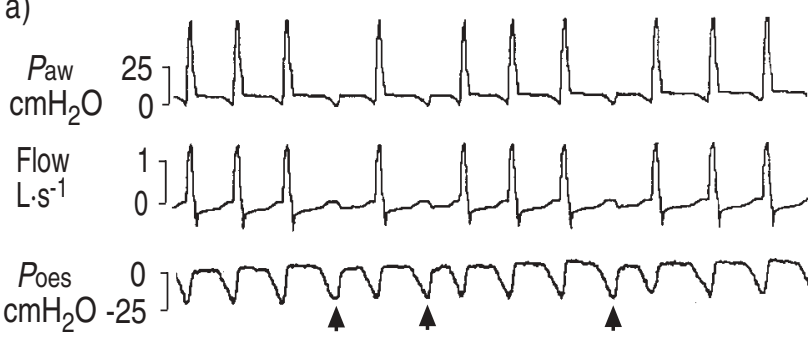

b)

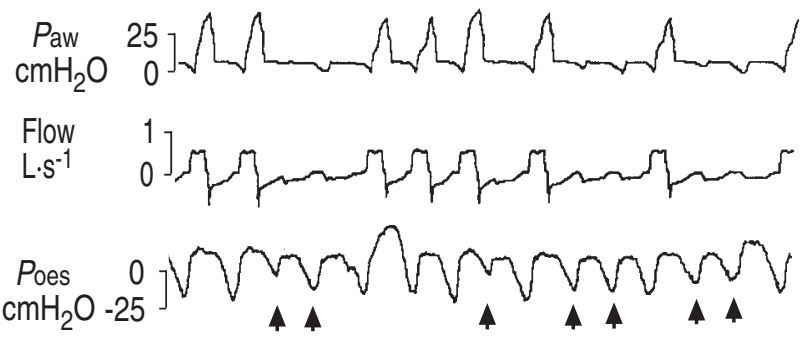

Fig. 2. - Airway pressure $(P$ aw $)$, flow and oesophageal pressure $\left(P_{\mathrm{oes}}\right)$ in a patient with chronic obstructive pulmonary disease ventilated on assist volume-controlled mode with two different inspiratory flow rates $\left(V^{\prime} \mathrm{I}\right)$ : a) $90 \mathrm{~L} \cdot \mathrm{min}^{-1}$; and b) $30 \mathrm{~L} \cdot \mathrm{min}^{-1}$. Tidal volume was kept constant $(0.55 \mathrm{~L})$. Missing efforts are indicated by arrows. See text for further details. (fig. 2a) and on another to $30 \mathrm{~L} \cdot \mathrm{min}^{-1}$ (fig. 2b). Several important points are illustrated by the figure. At both 90 and $30 \mathrm{~L} \cdot \mathrm{min}^{-1}$ values of $V^{\prime}$ I a significant number of missing efforts occurred. These missing efforts can be identified using $P$ aw, flow or $P_{\text {oes }}$ waveforms. An abrupt decrease in $P$ aw and $P$ oes during expiration and hesitation in expiratory flow, which are not followed by machine-delivered breath, indicate missing effort. At $V^{\prime}$ I of 90 $\mathrm{L} \cdot \mathrm{min}^{-1}$, the rate of machine cycles was 17 breaths $\cdot \mathrm{min}^{-1}$, whereas the patient's spontaneous rate was 22 breaths. $\min ^{-1}$. Minute ventilation, determined by ventilator rate and $V \mathrm{~T}$, was $9.4 \mathrm{~L} \cdot \mathrm{min}^{-1}$. By changing $V^{\prime} \mathrm{I}$ to $30 \mathrm{~L} \cdot \mathrm{min}^{-1}$, it can be observed that there was a decrease in machine rate and ventilation to 13 breaths $\mathrm{min}^{-1}$ and 6.2 $\mathrm{L} \cdot \mathrm{min}^{-1}$, respectively, despite the fact that patient's breathing frequency increased to 24 breaths $\cdot \mathrm{min}^{-1}$. Furthermore, note that a considerable portion of inspiratory muscle pressure needs to trigger the ventilator; and, in some breaths, all the muscle pressure is dissipated to trigger the venti-lator and, therefore, neural inspiratory time ends when machine inspiratory time starts. It is obvious that the machine cycles out of phase with the patient and the discrepancy varies substantially from breath to breath. Finally, observe that when $P$ oes swings are decreased the likelihood of missing effort increases. This indicates that, for a given degree of PEEPi, missing effort is more likely to occur when the $P$ mus is small, such as when the muscles are fatigued and/or weak or when central drive is low (i.e. low $\mathrm{Pa}_{\mathrm{a}}, \mathrm{CO}_{2}$ ).

The phenomenon of missing efforts has been studied in detail, on theoretical ground, by Younes [15, 23], who used a model of the respiratory system to examine the relationship between machine rate and spontaneous breathing frequency during various modes of support (AVC, PS and PAV). His analysis indicates that, for given mechanical properties of the respiratory system, the relationship is not simple and is influenced by the level of assist ventilation, the intensity of patient effort and the spontaneous breathing frequency. Increased assist level, spontaneous patient breathing rate and decreased intensity of patient effort are associated with greater discrepancy between patient and ventilator (fig. 3). The likelihood of missing efforts was less with PAV, probably because neural timing and drive is tightly linked to ventilator timing and $V \mathrm{~T}$.

To summarize the observations on missing efforts: 1 ) the rate of the machine's cycles does not reflect the patient's spontaneous breathing frequency. 2) at constant patient breathing frequency, the rate of the machine's cycle may be influenced by $P$ mus, an index of $V$ T demand (i.e. drive). Any factor that affects $P$ mus may also affect ventilator frequency and thus, paradoxically, stimuli that increase drive may actually affect machine rate; 3 ) at constant patient breathing frequency and $P$ mus, manipulation of the assist level (pressure or volume assist), machine inspiratory time and cycling-off criteria may change the machine's rate; and 4) decrease in patient breathing frequency may decrease the proportion of missing effort by prolonging expiratory time. This may increase the machine's rate and vice versa.

It is obvious from the above considerations that the phenomenon of missing effort has a considerabe affect on the interpretation of ventilatory output in relation to the control of breathing during mechanical ventilation. 
a)
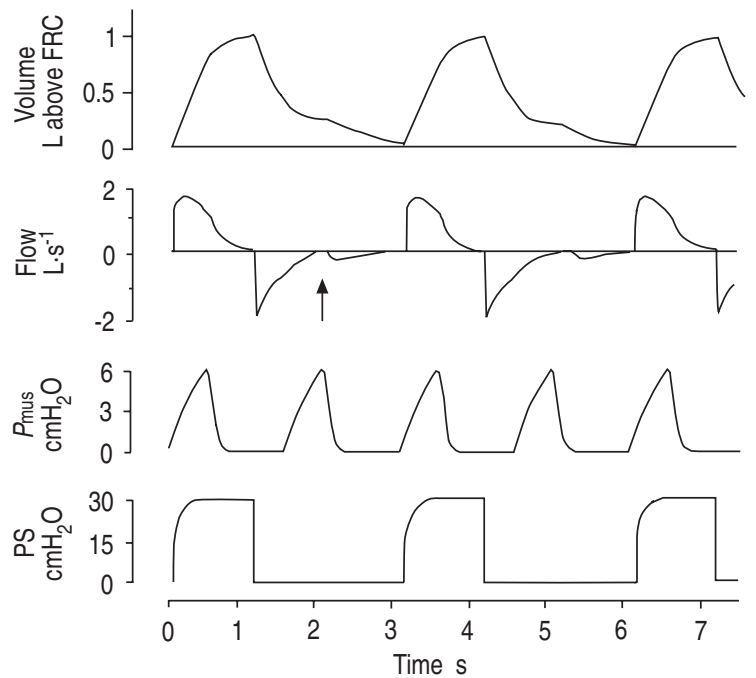

b)
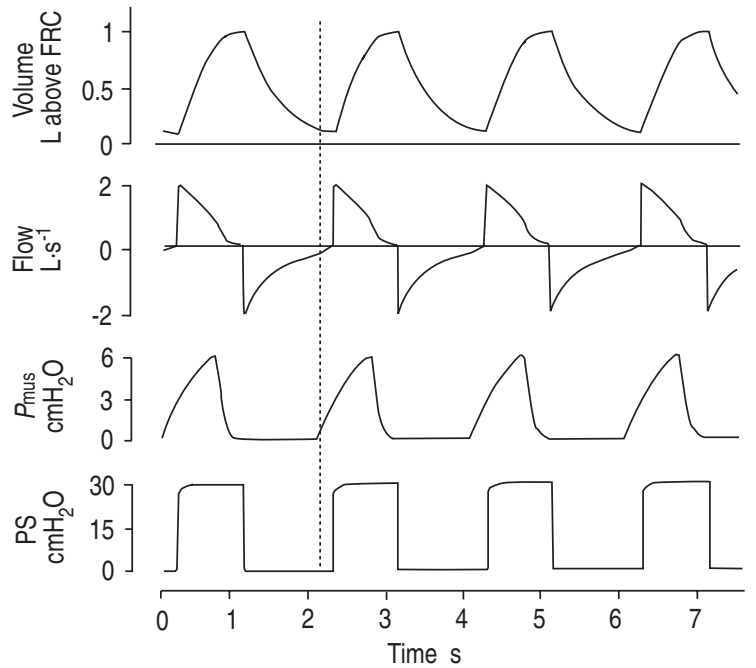

Fig. 3. - Volume, airflow, muscle pressure ( $P$ mus $)$ and airway pressure in a simulated patient with obstructive lung disease ventilated on pressure-support (PS) mode. a) The ventilator is triggered every other spontaneous inspiratory effort. Ventilator rate is 20 cycles $\cdot \mathrm{min}^{-1}$, while the patient's spontaneous breathing frequency is 40 breaths $\cdot \mathrm{min}^{-1}$ (arrow indicates missing effort). b) Keeping the same $P$ mus, patient's rate decreases from 40 to 30 breaths. $\mathrm{min}^{-1}$, allowing more time for expiration. This causes a reduction in the magnitude of dynamic hyperinflation and, as a result, each inspiratory effort triggers the ventilator. The ventilator rate increases to $30 \mathrm{cycles} \cdot \mathrm{min}^{-1}$, while the patient's rate has actually decreased. Notice in both figure $3 a$ and $b$ the discrepancy between neural and machine inspiratory and expiratory time. (Vertical dotted line indicates the beginning of inspiratory effort). (From YounEs [15], with permission).

Furthermore, with missing efforts, significant alteration in patient effort occurs due to changes in feedback loop. Failure of the ventilator to respond to patient inspiratory effort may alter mechanical, chemical, reflex and behavioural feedback, thus, secondarily affecting the intensity and rate of the patient's respiratory effort (fig. 1).

\section{Retriggering}

With retriggering the ventilator is triggered more than once during the same inspiratory effort [15, 23]. This may occur if the patient inspiratory effort is vigorous and longer than mechanical inflation time. In which case,

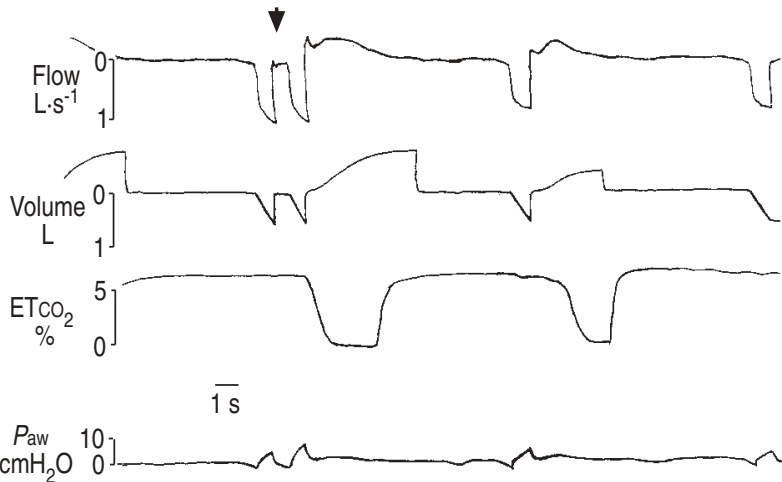

Fig. 4. - Flow (inspiration down), volume (inspiration down), endtidal $\mathrm{CO}_{2}\left(\mathrm{ETCO}_{2}\right)$ and airway pressure $(P \mathrm{aw})$ in a normal subject ventilated on assist volume-controlled mode. Note double-triggering (arrow) when inspiratory flow was $1 \mathrm{~L} \cdot \mathrm{s}^{-1}$. This occurred because mechanical inspiratory time, which was preset by ventilatory settings, was considerably shorter than neural inspiratory time. In this case, $P$ mus immediately after inflation, decreased $P$ aw below the threshold for triggering and caused the ventilator to recycle. The actual tidal volume $(V \mathrm{~T})$ delivered to the subject and the ventilator rate are double the predetermined $V_{\mathrm{T}}$ (note the expired $V \mathrm{~T}$ ) and spontaneous subject breathing frequency, respectively. Changing inspiratory flow from 60 to 50 $\mathrm{L} \cdot \mathrm{min}^{-1}\left(V_{\mathrm{T}}\right.$ was kept constant) increased mechanical inflation time from 0.6 to $0.8 \mathrm{~s}$ and double-triggering did not occur. Observe, also, the difference in $\mathrm{ETCO}_{2}$ between the breaths with and without doubletriggering.

at the end of mechanical inspiration, $P$ mus continues to increase and, because inspiratory flow is zero or is reversed, it is dissipated to overcome the elastic recoil alone. Thus, there might be a situation where $P$ mus is greater than elastic recoil, causing airway pressure to decrease below PEEP and this triggers the ventilator (fig. 4). Retriggering may occur with PS or AVC. On the other hand, retriggering does not occur with PAV because, with this mode, $P$ mus is the variable that controls gas delivery. Short mechanical inflation time may promote retriggering (fig. 4). With the phenomenon of retriggering, machine rate overestimates patient spontaneous breathing frequency. Furthermore, as with missing efforts, retriggering might change the patient effort if alterations in various feedback systems occur (figs. 1 and 4).

\section{Response of patient effort to ventilator-delivered breath}

\section{Mechanical feedback}

Mechanical feedback describes the well-known effects of length (volume) and velocity of contraction (flow) of respiratory muscles, as well as of geometrical factors on $P$ mus $[6,7,27]$. For a given level of muscle activation, $P$ mus decreases with increasing lung volume and flow. Thus, for similar neural output to respiratory muscles, $P$ mus should be smaller during mechanical ventilation than during spontaneous breathing if pressure provided by the ventilator results in greater flow and volume. The consequences of mechanical feedback in mechanicallyventilated patients are not known. However, the effects of mechanical feedback on Pmus would be small if volume and flow are low relative to their maximum values $[28,29]$. During mechanical ventilation, the operating volume and flow are relatively low $[3,4]$, indicating that 
mechanical feedback is not very important for mechanically-ventilated patients. Nevertheless, it is possible that this type of feedback may be of clinical significance in patients with high ventilatory requirements and/or impaired neuromuscular competence. Furthermore, in the presence of dynamic hyperinflation inspiratory muscles are forced to operate at high lung volume, which is a disadvantageous position for pressure generation [30-32]. Therefore, mechanical feedback, by reducing $P$ mus, might increase the number of missing efforts in patients with dynamic hyperinflation.

\section{Chemical feedback}

One of the main objectives of mechanical ventilation is to unload the respiratory muscles [3]. It would be interesting to see the effects of respiratory muscle unloading on control of breathing. Theoretically, the respiratory system can follow one of three courses in response to unloading: 1) respiratory muscle activation is downregulated, so that the same ventilation as before the unloading is obtained; 2) respiratory muscle activation remains unchanged and, therefore, ventilation increases according to the degree of unloading; and 3) there may be an intermediate response, whereby ventilation is higher at a lower level of respiratory muscle activity. It is generally believed that the respiratory system follows the third course; with unloading, ventilation is higher and respiratory motor output is lower [16, 33, 34]. Whilst these findings indicate that reflex feedback related to the load per se plays a role in determining the level of respiratory muscle activation, the results of such studies fail to provide information about the relative importance of such feedback. This is because these studies were performed using an open loop system and, therefore, chemical feedback was not strictly comparable with and without unloading. Thus, the observed downregulation of respiratory muscle output could have been related to associated reduction of chemical feedback produced by the higher ventilation. In an open system, chemical feedback cannot be discounted on the grounds that partial pressure of oxygen or carbon dioxide $\left(\mathrm{PO}_{2}\right.$ or $\left.\mathrm{PCO}_{2}\right)$ did not change "significantly".

The ability of respiratory muscle unloading to downregulate respiratory motor output has been questioned by several pieces of evidence. Data from patients during constant flow synchronized intermittent mandatory ventilation (SIMV) have shown that for a given level of assist, inspiratory effort did not differ between spontaneous and mandatory breaths $[35,36]$. These results indicate that inspiratory output is preprogrammed and is relatively insensitive to breath-by-breath changes in load seen during SIMV. Chemical feedback could be a critical factor for this breath programming. These results have recently been challenged by GIULIANI et al. [37], who showed that the mode of mechanical ventilation is important to show an effect of unloading on respiratory effort. They demonstrated that inspiratory effort was smaller in mandatory breaths than in spontaneous only if SIMV is applied with flow-triggering and constant pressure. However, in this study, respiratory effort was quantitated using oesophageal pressure, which complicates the interpretation of the results. With pressure assist ventilation, changes in oesophageal pressure do not reflect changes in respiratory muscle pressure and, thus, in patient effort [16]. Furthermore, oesophageal pressure was related to static recoil pressure of the chest wall and was not corrected for flow resistance [16, 32]. It follows that with high inspiratory flows, observed with constant pressure, inspiratory effort was underestimated, making the interpretation of the results complicated.

Recently, using a rebreathing method, we studied the response of neuromuscular output to $\mathrm{CO}_{2}$ with and with-out unloading of the respiratory system [38]. The unloading was achieved using PAV. At similar $\mathrm{PCO}_{2}$ in peripheral and central chemoreceptors, neuromuscular output, expressed by transdiaphragmatic pressure and total pressure generated by all respiratory muscles, remained virtually unchanged by an approximately $50-60 \%$ reduction of the normal mechanical load; the neuromuscular output was tightly linked to $\mathrm{CO}_{2}$ and not to load reduction. These results indicate that increasing the assist level in mechanically-ventilated subjects unloads the respiratory muscles only to the extent that $P_{\mathrm{CO}_{2}}$ decreases. The degree of downregulation should depend on the sensitivity to $\mathrm{CO}_{2}$ and the magnitude of $\mathrm{PCO}_{2}$ reduction. Notwithstanding that the response to unloading might be related, to some extent, to baseline mechanical load or to the mode of mechanical ventilation [37], these results emphasize the importance of chemical feedback during mechanical ventilation. Paradoxically, the role of chemical feedback has been largely ignored by studies dealing with the effect of mechanical ventilation on respiratory muscle activity.

The effectiveness of chemical feedback to compensate for changes in chemical stimuli in mechanically-ventilated patients is a complicated issue. During controlled mechanical ventilation (CMV), an increase in chemical stimulus $\left(\mathrm{Pa}, \mathrm{CO}_{2}\right.$ or arterial oxygen tension $\left.\left(\mathrm{Pa}, \mathrm{O}_{2}\right)\right)$ cannot elicit any ventilatory response, because the ventilator does not increase its rate or its $V \mathrm{~T}$ in response to patient effort. With assist modes of mechanical ventilatory support, the patient, theoretically, has the option to change ventilation as a result of chemical feedback. With constant flow SIMV, a change in chemical stimuli may elicit a ventilatory response only through alterations in the characteristics of spontaneous breaths, while mandatory breaths are independent of patient effort, a situation similar to that during CMV. In patients ventilated on AVC mode, the respiratory system can compensate for changes in chemical stimuli through breathing frequency, but not through the intensity of patient effort. On the other hand, with pressure assisted modalities of ventilatory support (PS or PAV) the ventilator delivers a $V \mathrm{~T}$ which varies with the intensity of patient effort. In this case, the ventilator has the ability to respond to both components of the ventilatory response to change in chemical stimuli (fig. 5). It follows that with pressureassist, chemical feedback may better control arterial blood gas values.

What happens in reality? We are all familiar with a patient ventilated on assist modes, who although having an intact central drive and normal or near normal respiratory system mechanics, develops respiratory alkalosis or acidosis as a result of an inappropriate assist level, a change in metabolic demands, or a change in gas exchange properties of the lung. Notwithstanding the 

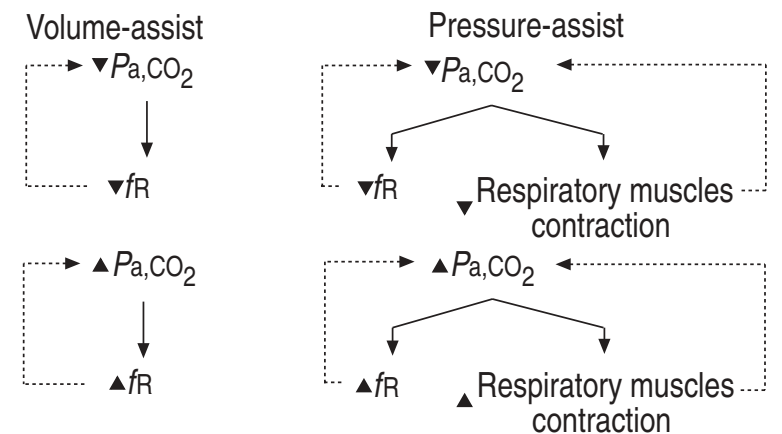

Fig. 5. - Pathways that the respiratory system can use in order to compensate for change in arterial carbon dioxide tension $\left(\mathrm{Pa}_{\mathrm{a}}, \mathrm{CO}_{2}\right)$ during volume-controlled and pressure-assist modes of synchronized (pressure- or flow-triggering) mechanical ventilatory support. $\boldsymbol{\nabla}$ : decrease; $\boldsymbol{\Delta}$ : increase; $f_{\mathrm{R}}$ : respiratory frequency. Pmus: pressure generated by respiratory muscles. See text for details.

differences between volume and pressure assist, as far as the response of the ventilator to patient effort is concerned, the pati-ent with both modes of ventilatory support, through chemi-cal feedback, should be able to maintain a constant $P \mathrm{a}, \mathrm{CO}_{2}$, by appropriate adjustments in rate, intensity of respiratory effort, or both. Assuming normal activity of nonchemical inputs (mechanoreceptors, irritant receptors, cortical influence), failure to maintain a constant $P \mathrm{a}, \mathrm{CO}_{2}$ may imply either a defect or reduced effectiveness of chemical feedback during mechanical ventilation. This issue is of paramount importance in understanding the relationship between chemical feedback and mechanical ventilation, and the following observations may help us to clarify it.

Awake normal humans ventilated on AVC or PS with a relatively high $V \mathrm{~T}$ were seen to develop hypocapnia [39-42]. This was due to the fact that the subjects continued to trigger the ventilator rhythmically despite high tidal volumes and hypocapnia. Manipulation of $\mathrm{PCO}_{2}$ over a wide range had no appreciable effect on breathing frequency $[39,40]$. On the other hand, the intensity of respiratory effort, quantified from changes in airway pressure at constant flow and volume, rate of decline of airway pressure prior to triggering, $V \mathrm{~T}$ and mouth occlusion pressure at $0.1 \mathrm{~s}$ from the onset of inspiratory effort $(P 0.1)$ increased as a function of $P_{C_{2}}[39,40]$. It is of interest to note that the response was evident even in the hypocapnic range [39] (fig. 6). These results indicate that in mechanically-ventilated, awake humans: 1) breathing frequency is relatively insensitive to $\mathrm{CO}_{2}$ over a wide range of $\mathrm{PCO}_{2} ; 2$ ) the intensity of respiratory effort increases with increasing $\mathrm{PCO}_{2}$, even below eucapnic levels; and 3) the ventilatory response to $\mathrm{CO}_{2}$ is expressed mainly by intensity of respiratory effort.

These observations have at least two important consequences that should be taken into consideration in the management of mechanically-ventilated patients. Firstly, PS and AVC modes of mechanical ventilation greatly compromise the ability of chemical feedback to control $\mathrm{PCO}_{2}$. This is because, with AVC, the ventilator once triggered delivers a fixed $V \mathrm{~T}[3,4]$, whilst with PS, in the absence of active termination of inspiration, the $V \mathrm{~T}$ has a minimum value which depends on PS level, mechanical properties of the respiratory syste, and the cyclingoff criterion [14, 23]. It follows that, with both modes of support breathing, frequency plays a key role in

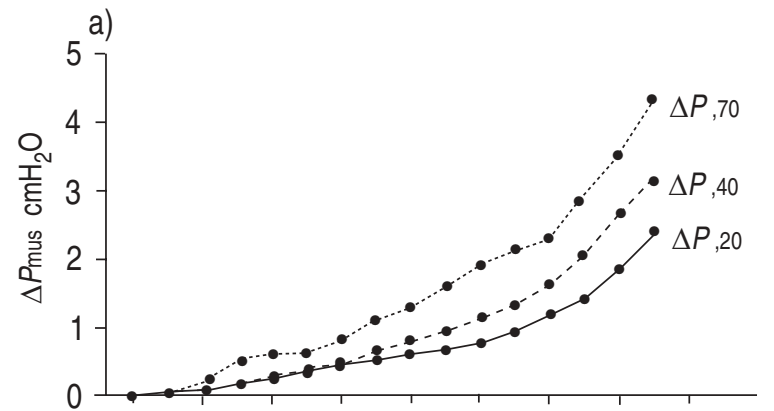

b)

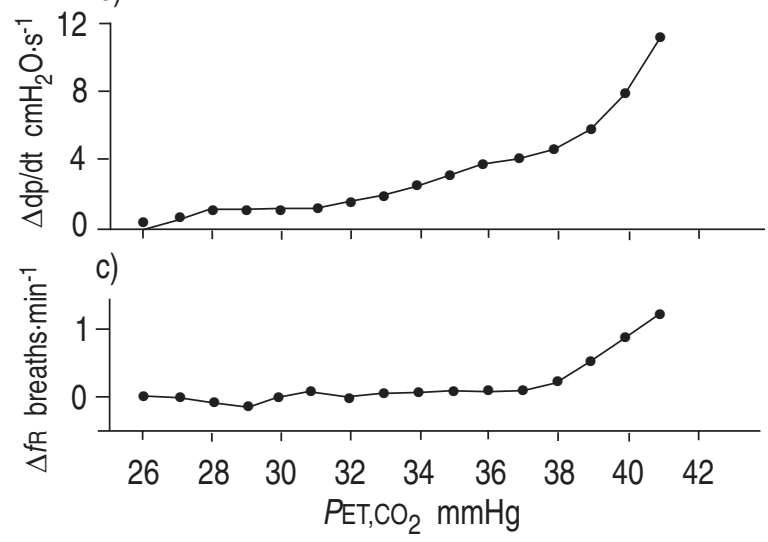

Fig. 6. - Changes in a) pressure generated by respiratory muscles $(\Delta P$ mus $)$ at different fractions of mechanical inflation time, $\mathrm{b})$ rate of decline of airway pressure before triggering $(\Delta \mathrm{dp} / \mathrm{dt})$ and $\mathrm{c})$ breathing frequency $(\Delta f \mathrm{R})$ as a function of end-tidal $\mathrm{CO}_{2}$ tension $\left(\mathrm{PETCO}_{2}\right)$ in normal subjects mechanically-ventilated on assist volume-controlled mode. $\Delta P$ mus and $\Delta \mathrm{dp} / \mathrm{dt}$ reflect changes in the intensity of respiratory effort. $\Delta P, 70, \Delta P, 40$ and $\Delta P, 20: \Delta P$ mus at 70,40 and $20 \%$ of mechanical inflation time, respectively. Note that the intensity of respiratory effort increases with increasing $\mathrm{PCO}_{2}$ stimulus even at low $P$ ET, $\mathrm{CO}_{2}$. $f \mathrm{R}$ remains relative constant over a wide range of $P \mathrm{ET}, \mathrm{CO}_{2}$. (From PATRICK et al., [39], with permission).

defending respiratory alkalosis. To the extent that breathing frequency is insensitive to $\mathrm{CO}_{2}[39,40]$, mechanically-ventilated awake subjects may easily develop respiratory alkalosis due to inappropriately high assist levels, reduced metabolic rate, or improvement in gas exchange properties of the lung.

Secondly, because the ventilatory response to $\mathrm{CO}_{2}$ is expressed mainly by the intensity of respiratory effort [39], PS mode, which permits $V$ T to change in response to patient effort [14], may, in contrast to AVC, compensate for changes in $\mathrm{PCO}_{2}$. We should mention, however, that the compensation during PS is partial because of the minimum $V \mathrm{~T}$ delivered (see above) and the limited ability of respiratory effort to modulate $V \mathrm{~T}$, particularly in patients with abnormal mechanical properties of the respiratory system $[15,23]$. PAV may permit better control of patient effort to ventilator-delivered variables [43], due to the fact that the volume-time profile and ventilator timing are tightly linked to $P$ mus $[4,15]$. Indeed, it has been demonstrated in patients ventilated on PAV, that ventilation and breathing pattern did not change appreciably as assist level was varied from near maximum to the lowest tolerable [43]. However, this mode is currently under investigation and we cannot comment on it further.

Although the above studies used $\mathrm{CO}_{2}$ as a stimulus, similar principles should apply if $\mathrm{PO}_{2}$ is altered. In 
steady-state, the effects of $\mathrm{CO}_{2}$ and $\mathrm{O}_{2}$ on breathing pattern are qualitatively similar; increasing the $\mathrm{O}_{2}$ or $\mathrm{CO}_{2}$ stimulus affects mainly the intensity of respiratory effort, while the response of breathing frequency is significantly less [8].

We should be aware that the effect of mechanical ventilation on control of breathing as far as chemical feedback is concerned might be modulated by various disease states. It has been shown in awake patients with obstructive sleep apnoea [44], and in patients with brain damage [45], that a drop in $\mathrm{PCO}_{2}$ because of brief (40 s) hypoxic hyperventilation, resulted, in contrast to normal subjects, in significant hypoventilation. When hypoxia was sustained for much longer ( $25 \mathrm{~min}$ ), hypoventilation was observed even in normals [46]. This hypoventilation was interpreted as evidence of a defect or reduced effectiveness of short-term poststimulus potentiation, a brain stem mechanism promoting ventilatory stability [46, 47]. To the extent that mechanical ventilation may represent a type of forced hyperventilation, these results could apply in mechanically-ventilated patients. High assist levels in these patients may decrease $P \mathrm{a}, \mathrm{CO}_{2}$ and trigger periodic breathing. Nevertheless, further studies are needed that will test the ventilatory response to chemical stimuli during various modes of ventilatory support, as well as the effects of disease.

So far, we have discussed chemical feedback during wakefulness. The picture is completely different during sleep or under anaesthesia. Several studies have shown that, under these circumstances, the maintenance of respiratory rhythm is critically dependent on chemical feedback [41, 48-50]. Reducing $\mathrm{Pa}, \mathrm{CO}_{2}$ by only a few $\mathrm{mmHg}$ causes apnoea. In the face of mechanical ventilatory support with assist modes, there are compensatory changes in breathing pattern, so that $\mathrm{PCO}_{2}$ is forced to remain around the $\mathrm{CO}_{2}$ set-point [41]. Thus, if pressure support or volume assist are set at values higher than those required for eucapnia or for $\mathrm{Pa}, \mathrm{CO}_{2}$ set-point, periodic or irregular breathing may be caused (fig. 7). These episodes may be associated with significant hypoxaemia, an issue of great importance for critically ill patients. However, it should be mentioned that in the presence of active lung disease, input to the respiratory controller from nonchemical sources [51] may not permit chemical feedback to prevent respiratory alkalosis during sleep or under anaesthesia.

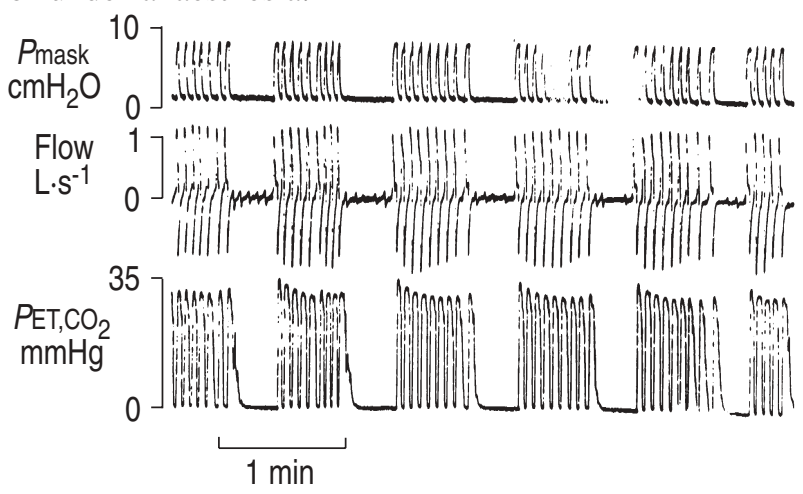

Fig. 7. - Airway pressure ( $P$ mask), flow, and end-tidal carbon dioxide tension $\left(P \mathrm{ET}, \mathrm{CO}_{2}\right)$ in a normal subject ventilated noninvasively (nose-mask) on pressure-support during non-rapid eye movement (NREM) sleep. Note that this subject exhibited periodic breathing as a result of mechanical ventilatory support. (From Morrell et al., [41], with permission).
Periodic or irregular breathing during sleep as a result of mechanical ventilatory support may be prevented or attenuated with PAV, which does not guarantee a minimum VT. Indeed, MEzA et al. [52] have shown, in normal sleeping subjects, that mechanical ventilation with PAV was not associated with periodic or irregular breathing. They observed that $V \mathrm{~T}$, respiratory frequency $(f \mathrm{R})$ and end-tidal carbon dioxide tension $\left(\mathrm{PETCO}_{2}\right)$ remained relatively stable, even at the highest assist level. These results indicate that during sleep PAV permits chemical feedback to regulate breath-by-breath arterial blood gas values.

In summary, the effectiveness of chemical feedback to compensate for changes in chemical stimuli during mechanical ventilation depends on: 1) the mode of mechanical ventilatory support; and 2) the sleep/awake stage. Failure to appreciate the role and limitations of chemical feedback during mechanical ventilation may lead to serious consequences for patient management. Diseases that may alter the response to mechanical ventilation should always be a consideration.

\section{Reflex feedback}

Reflex feedback plays an important role in control of breathing $[1,2]$. The characteristics of each breath are influenced by various reflexes, which are related to lung volume or flow and mediated by receptors located in the respiratory tract, lung and chest wall $[9,10]$. Most of our knowledge about the effects of these reflexes on control of breathing has been obtained from animal studies [5355]. Very little is known about the relevance of these reflexes to mechanical ventilation and much work needs to be done. A few points, however, deserve some comment.

Static and dynamic changes in lung volume elicit responses mediated by vagal and chest wall receptors $[9,10,15,23,53,54]$. In addition, it has been shown that controlled mechanical ventilation results in the generation of a $V \mathrm{~T}$-dependent inhibitory input to inspiratory muscles, mediated by an unidentified pathway $[56,57]$. All of these reflexes related to lung volume influence the breathing pattern in a complex way. The final response depends on the magnitude and type of lung volume change, the level of consciousness, and the relative strength of the reflexes involved $[15,23]$. At present, the role of the above reflexes on mechanically-ventilated patients is unclear.

Currently, in mechanically-ventilated patients inspiratory flow rates are adjusted mainly for the purpose of enhancing patient-ventilator interaction and of changing inspiratory time, and, thus, affecting airway pressures, dynamic hyperinflation, haemodynamic status and distribution of ventilation [37, 58, 59]. However, inspiratory flow rates may affect respiratory output in a way that has been largely ignored in patient management. It has been shown, in mechanically-ventilated normal subjects, that increasing inspiratory flow rate exerted an excitatory reflex effect on respiratory output; increasing inspiratory flow was associated with an increase in central drive and breathing frequency, and a decrease in expiratory time $[60,61]$. This effect was complete in one breath after a change in flow rate, and persisted, although to a lesser degree, during non-rapid eye movement (NREM) sleep [60] (fig. 8). The strength of this reflex was not 

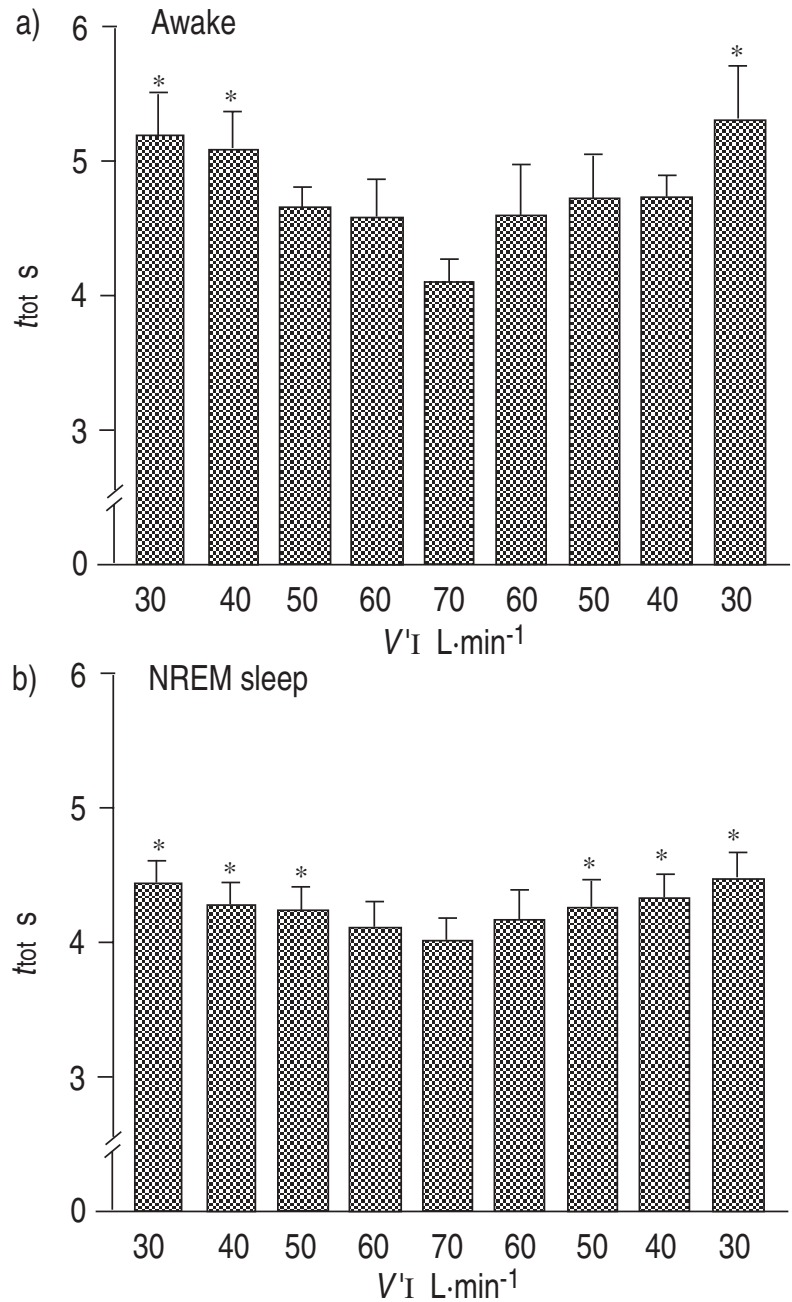

Fig. 8. - Total breath duration ( $t$ tot $)$ as a function of constant inspiratory flow $\left(V^{\prime} \mathrm{I}\right)$ in normal subjects ventilated on assist volume-controlled mode, during: a) wakefulness; and b) non-rapid eye movement (NREM) sleep. Both during wakefulness and NREM sleep, $t$ tot decreases in a graded and reversible manner as $V^{\prime}$ I increases and decreases, respectively. The response was attenuated by NREM sleep. (From GEORgopoulos et al., [60], with permission). Bars are SEM. *: significant diference from $t$ tot at $70 \mathrm{~L} \cdot \mathrm{min}^{-1}(\mathrm{p}<0.05)$.

affected by breathing route (nose or mouth), temperature and volume of inspired gas and anaesthesia of upper and lower airways [61]. Presumably, the excitatory effect of inspiratory flow is mediated through receptors located deep in the airway mucosa or chest wall.

There are at least four implications for the mechanically-ventilated patient, as far as this reflex is concerned. Firstly, an increase in assist level intended to decrease respiratory effort is likely $[37,59]$ to be less effective than planned because of the stimulating effect of the concomitant increase in flow. Secondly, high inspiratory flow rates may cause hyperventilation and respiratory alkalosis, an important cause of various arrhythmias and weaning failure $[62,63]$. Thirdly, the desired effect of flow on expiratory time [58] may not be achieved (fig. 9). Fourthly, the ventilatory consequences of flow are likely to be different depending on sleep/awake stage. Collectively, these observations indicate that the excitatory effect of flow rate may modify expected responses to change in ventilatory settings, thus, affecting therapeutic decisions.

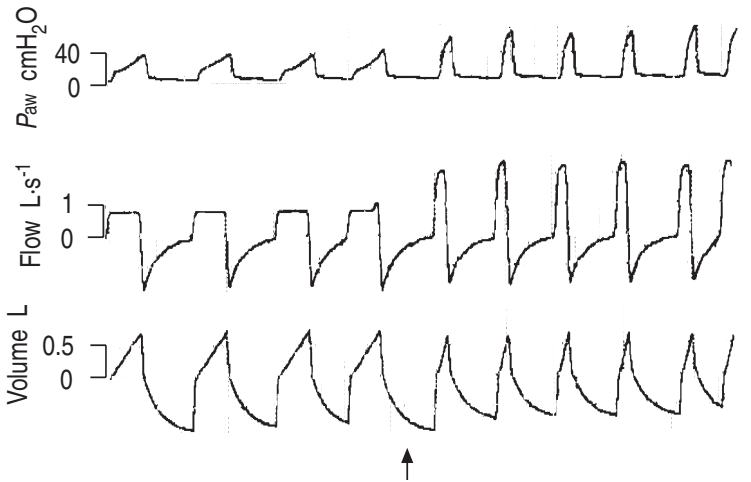

Fig. 9. - Airway pressure $(P a w)$, flow, and volume (inspiration positive) in a patient with obstructive lung disease ventilated on assist volume-controlled mode. The arrow indicates the point at which constant inspiratory flow $\left(V^{\prime} \mathrm{I}\right)$ increased from 30 to $90 \mathrm{~L} \cdot \mathrm{min}^{-1}$ (tidal volume was kept constant). Notice that within one breath after a change in $V^{\prime}$ I, total breath duration decreased considerably. This excitatory effect of $V^{\prime}$ I on the rate of inspiratory effort counterbalances the beneficial effect of high $V^{\prime}$ I on expiratory time.

\section{Behavioural feedback}

The effects of behavioural feedback on control of breathing during mechanical ventilation are unpredictable, depending on several factors related to an individual patient, ventilatory settings and intensive care unit (ICU) environment [11, 12]. Ventilatory strategies intended to achieve a particular goal might be ineffective in awake patients due to behavioural responses. For example, it has been shown in mechanically-ventilated normal subjects, that both higher and lower than spontaneous inspiratory flow increases the sense of dyspnoea [64]. Thus, in awake patients a change in inspiratory flow may cause discomfort and alteration in patient effort. Similarly, increasing the assist level, which inevitably increases the airway pressure [3, 4], may force the patient to fight the ventilator. Indeed, JuRBan et al. [65], in patients with COPD, increased the pressuresupport level and observed expiratory efforts, while the ventilation was still inflating the thorax. This neuralmechanical dyssynchrony can be very uncomfortable, as is well-recognized with the use of inverse-ratio ventilation. Furthermore, active expiratory efforts in patients with flow limitation during passive expiration cause dynamic compression in the airways downstream and an unpleasant sensation [66]. Discomfort related to ventilatory settings may be manifested with rapid shallow breathing (panic reaction) leading to a vicious cycle [67]. Finally, we should recognize that ventilatory settings that seem satisfactory during sleep, where behavioural feedback is absent, may become a source of discomfort during wakefulness with unpredictable effects on patient status.

\section{Conclusion}

To summarize, mechanical ventilation considerably influences the control of breathing, as well as its expression. During mechanical ventilation, the respiratory system is under the influence of two pumps, the ventilator pump $(P$ aw $)$ and the patient's own respiratory muscles (Pmus). The physician dealing with a mechanically-ventilated patient should be aware that: 1) ventilatory output may not reflect patient effort; and 2) various aspects 
of control of breathing may be masked or modulated by mechanical ventilation. Guidelines for mechanical ventilatory support must take into consideration the interaction between patient feedback (chemical, reflex, mechanical and behavioural) and ventilator-delivered breath.

\section{References}

1. Younes M, Remmers J. Control of tidal volume and respiratory frequency. In: Hornbein TF, ed. Lung Biology in Health and Disease. Regulation of Breathing New York, Marcel Dekker, 1981; 17: pp. 621-671.

2. Berger AJ. Control of breathing. In: Murray JF, Nadel JA, eds. Textbook of Respiratory Medicine. Philadelphia, W.B. Saunders, 1988; pp. 49-166.

3. Slutsky AS. Mechanical ventilation. ACCP consensus conference. Chest 1993; 104: 1833-1859.

4. Younes M. Proportional assist ventilation, a new approach to ventilatory support: theory. Am Rev Respir Dis 1992; 145: 114-120.

5. Mead J, Agostoni E. Dynamics of respiration. In: Fenn WO, Rahn H, eds. Handbook of Physiology. Section 3. Vol. I. Respiration. Washington, DC, American Physiological Society, 1964; pp. 411-427.

6. Bigland B, Lippold OCJ. The relation between force, velocity and integrated electrical activity in human muscles. J Physiol (Lond) 1954; 123: 214-224.

7. Grassino A, Goldman MD, Mead J, Sears TA. Mechanics of the human diaphragm during voluntary contraction: statics. J Appl Physiol: Respirat Environ Exercise Physiol 1978; 44: 829-839.

8. Cunningham DJC, Robbins PA, Wolff CB. Integration of respiratory responses to changes in alveolar partial pressures of $\mathrm{CO}_{2}$ and $\mathrm{O}_{2}$ and in the arterial $\mathrm{pH}$. In: Cherniack NS, Widdicombe JC, eds. Handbook of Physiology. The Respiratory system. Vol. 2. Bethesda, MD, American Physiological Society, 1986; pp. 475528.

9. Coleridge HM, Coleridge JCG. Reflexes evoked from tracheobronchial tree and lungs. In: Cherniack NS, Widdicombe JC, eds. Handbook of Physiology. The Respiratory System. Vol. 2. Bethesda, MD, American Physiological Society, 1986; pp. 395-430.

10. Shannon R. Reflexes evoked from respiratory muscles and cortovertebral joints. In: Cherniack NS, Widdicombe JG, eds. Handbook of Physiology. The Respiratory system. Vol. 2. Bethesda, MD, American Physiological Society, 1986; 431-438.

11. Killian KJ, Campell EJM. Dyspnea. In: Roussos C, Macklem PT, eds. The Thorax. Lung Biology in Health and Disease. Vol. 29. New York, Marcel Dekker, 1985; pp. 787-928.

12. Altose MD. Dyspnea. Curr Pulmonol 1986; 7: 199-226.

13. Sassoon CSH. Mechanical ventilation design and function: the trigger variable. Respir Care 1992; 36: 815-828.

14. MacIntyre NR. Respiratory function during pressure support ventilation. Chest 1986; 89: 677-683.

15. Younes M. Patient-ventilator interaction with pressureassisted modalities of ventilatory support. Semin Respir Med 1993; 14: 299-322

16. Younes M, Puddy A, Roberts D, et al. Proportional assist ventilation: results of an initial clinical trial. Am Rev Respir Dis 1992; 145: 121-129.

17. Marini JJ. Should PEEP be used in airflow obstruction? (Editorial). Am Rev Respir Dis 1989; 140: 1-3.
18. Pepe PE, Marini JJ. Occult positive end-expiratory pressure in mechanically-ventilated patients with airflow obstruction. Am Rev Respir Dis 1982; 126: 166-170.

19. Fleury B, Murciano D, Talamo C, Aubier M, Pariente R, Milic-Emili J. Work of breathing in patients with chronic obstructive pulmonary disease in acute respiratory failure. Am Rev Respir Dis 1985; 132: 822-827.

20. Rossi A, Gotfried SB, Higgs BD, Zocchi L, Grasino A, Milic-Emili J. Respiratory mechanics in mechanicallyventilated patients with respiratory failure. J Appl Physiol 1985; 58: 1849-1858.

21. Georgopoulos D, Giannouli E, Patakas D. Effect of extrinsic positive end-expiratory pressure on mechanically-ventilated patients with chronic obstructive pulmonary disease and dynamic hyperinflation. Intensive Care Med 1993; 19: 197-203.

22. Rossi A, Polese G, Brandi G, Conti G. Intrinsic positive end-expiratory pressure (PEEPi). Intensive Care Med 1995; 21: 522-536.

23. Younes M. Interactions between patients and ventilators. In: Roussos C, ed. Thorax. 2nd edn. Lung Biology in Health and Disease. Vol. 85, Chapter 81. New York, Marcel Dekker, 1995; pp. 2367-2420.

24. Fabry B, Guttmann J, Eberhard L, Bauer T, Haberthur C, Wolff G. An analysis of desynchronization between the spontaneous breathing patient and ventilator during inspiratory pressure support. Chest 1995; 107: 1387-1394.

25. Rossi A, Appendini L. Wasted efforts and dyssynchrony: is the patient-ventilator battle back? (Editorial). Intensive Care Med 1995; 21: 867-870.

26. Nava S, Bruschi C, Rubini F, Palo A, Iotti G, Braschi A. Respiratory response and inspiratory effort during pressure support ventilation in COPD patients. Intensive Care Med 1995; 21: 871-879.

27. Younes M, Riddle W. Relation between respiratory neural output and tidal volume. J Appl Physiol: Respirat Environ Exercise Physiol 1984; 56: 1110-1119.

28. Agostoni E, Fenn WO. Velocity of muscle shortening as a limiting factor in respiratory airflow. J Appl Physiol 1960; 15: 349-353.

29. Agostoni E, Mead J. Statics of the respiratory system. In: Fenn WO, Rahn H, eds. Handbook of Physiology. Section 3. Vol. I. Respiration. Washington, DC, American Physiological Society, 1964; pp. 387-409.

30. Roussos C, Macklem PT. The respiratory muscles. $N$ Engl J Med 1982; 307: 786-797.

31. Tobin MJ . Respiratory muscles in disease. Clin Chest Med 1988; 9: 263-286.

32. Roussos C, Campbell EJM. Respiratory muscles energetics. In: Macklem PT, Mead J, eds. Handbook of Physiology. The Respiratory System. Mechanics of breathing. Vol. 2. Bethesda, MD, American Physiological Society, 1986; pp. 481-509.

33. DeWeese EL, Sullivan TY, Yu PL. Ventilatory and occlusion pressure responses to helium breathing. J Appl Physiol: Respirat Environ Exercise Physiol 1984; 54: 1525-1531.

34. Hussain SNA, Pardy RL, Dempsey JA. Mechanical impedance as determinant of inspiratory neural driving during exercise in humans. J Appl Physiol 1985; 59: 365-375.

35. Marini JJ, Smith TC, Lamb VJ. External output and force generation during synchronized intermittent mechanical ventilation. Am Rev Respir Dis 1988; 138: 1169-1179.

36. Imsand C, Feihl F, Perret C, Fitting JW. Regulation of inspiratory neuromuscular output during synchronized 
intermittent mechanical ventilation. Anesthesiology 1994; 80: $13-22$.

37. Giuliani R, Mascia L, Recchia F, Caracciolo A, Fiore T, Ranieri VM. Patient-ventilator interaction during synchronized intermittent mandatory ventilation. Am J Respir Crit Care Med 1995; 151: 1-9.

38. Georgopoulos D, Mitrouska I, Webster K, Bshouty Z, Younes M. Effects of respiratory muscle unloading on the ventilatory response to $\mathrm{CO}_{2}$. Am J Respir Crit Care Med 1995; 151: A639.

39. Patrick W, Webster K, Puddy A, Sanii R, Younes M. Respiratory response to $\mathrm{CO}_{2}$ in the hypocapnic range in conscious humans. J Appl Physiol 1995; 79: 2058-2068.

40. Sceid P, Lofaso F, Isabey D, Harf A. Respiratory response to inhaled $\mathrm{CO}_{2}$ during positive inspiratory pressure in humans. J Appl Physiol 1994; 77: 876-882.

41. Morrell MJ, Shea SA, Adams L, Guz A. Effects of inspiratory support upon breathing during wakefulness and sleep. Respir Physiol 1993; 93: 57-70.

42. Mancedo J, Isabey D, Lorino H, Lofaso F, Lemaire F, Brochard L. Comparative effects of pressure support ventilation and intermittent positive pressure breathing (IPPB) in nonintubated healthy subjects. Eur Respir J 1995; 8: 1901-1909.

43. Marantz S, Patrick W, Webster K, Roberts D, Oppenheimer L, Younes M. Respiratory response to different levels of proportional assist (PAV) in ventilator-dependent patients. Am Rev Respir Dis 1992; 145: A525.

44. Georgopoulus D, Giannouli E, Tsara V, Argiropoulou P, Patakas D, Anthonisen NR. Respiratory short-term poststimulus potentiation (after-discharge) in patients with obstructive sleep apnea. Am Rev Respir Dis 1992; 146: 1250-1255.

45. Georgopoulus D, Mitrouska I, Kolestos K, et al. Poststimulus ventilation in patients with brain damage. Am J Respir Crit Care Med 199; 152: 1627-1632.

46. Georgopoulus D, Bshouty Z, Younes M, Anthonisen NR. Hypoxic exposure and activation of after-discharge mechanism in conscious humans. J Appl Physiol 1990; 69: 1159-1164.

47. Younes M. The physiologic basis of central apnea. Curr Pulmonol 1989; 10: 265-326.

48. Fink BR, Hanks EC, Ngai SH, Papper EM. Central regulation of respiration during anaesthesia and wakefulness. Ann NY Acad Sci 1963; 109: 892-899.

49. Skatrud JB, Dempsey JA. Interaction of sleep state and chemical stimuli in sustaining rhythmic respiration. $J$ Appl Physiol: Respirat Environ Exercise Physiol 1983; 55: 813-822.

50. Datta AK, Shea SA, Horner RL, Guz A. The influence of induced hypocapnia and sleep on the endogenous respiratory rhythm in humans. $J$ Physiol 1991; 440: 1733.

51. Rebuck AS, Slutsky AS. Control of breathing in diseases of the respiratory track and lungs. In: Cherniack NS, Widdicombe JC, eds. Handbook of Physiology. The Respiratory System. Control of Breathing. Vol. II. Part 2. Bethesda, MD, American Physiological Society, 1986; pp. 771-791.
52. Meza S, Giannouli E, Younes M. Ventilatory response to inspiratory muscle unloading with PAV during sleep. Am J Respir Crit Care Med 1995; 151 A: 639.

53. Clark FJ, Von Euler C. On the regulation of depth and rate of breathing. J Physiol 1972; 222: 267-295.

54. Grunstein MM, Younes M, Milic-Emili J. Control of tidal volume and respiratory frequency in anesthetized cats. J Appl Physiol 1973; 35: 463-476.

55. Pack AI, Delaney RG, Fishman AP. Augmentation of phrenic nerve activity by increased rates of lung inflation. J Appl Physiol: Respirat Environ Exercise Physiol 1981; 50: 149-161.

56. Altose MD, Castele RJ, Connors AF Jr, Dimarco AF. Effects of volume and frequency of mechanical ventilation on respiratory activity in humans. Respir Physiol 1986; 66: 171-180.

57. Simon PM, Skatrud JB, Badr MS, Griffin DM, Iber C, Dempsey JA. Role of airway mechanoreceptors in the inhibition of inspiration during mechanical ventilation in humans. Am Rev Respir Dis 1991; 144: 1033-1041.

58. Georgopoulos D, Mitrouska I, Markopoulou K, Patakas D, Anthonisen NR. Effects of breathing patterns on mechanically-ventilated patients with chronic obstructive pulmonary disease and dynamic hyperinflation. Intensive Care Med 1995; 21: 880-886.

59. Ward ME, Corbeil C, Gibbons W, Newman S, Macklem PT. Optimization of respiratory muscle relaxation during mechanical ventilation. Anesthesiology 1988; 69: 29-35.

60. Georgopoulos D, Mitrouska I, Bshouty Z, Webster K, Anthonisen NR, Younes M. Effects of breathing route, temperature and volume of inspired gas and airway anesthesia on the response of respiratory output to varying inspiratory flow. Am J Respir Crit Care Med 1996; 153: $168-175$.

61. Georgopoulos D, Mitrouska I, Bshouty Z, Anthonisen NR, Younes M. Effects of NREM sleep on the response of respiratory output to varying inspiratory flow. Am J Respir Crit Care Med 1996; 153: 1624-1630.

62. Ayres SM, Crace WJ. Inappropriate ventilation and hypoxemia as causes of cardiac arrhythmias: the control of arrhythmias without antiarrhythmic drugs. Am J Med 1969; 46: 495-505.

63. Pingleton SK. Complications of acute respiratory failure. Am Rev Respir Dis 1988; 137: 1463-1493.

64. Manning HL, Molinary EJ, Leiter JC. Effect of inspiratory flow rate on respiratory sensation and pattern of breathing. Am J Respir Crit Care Med 1995; 151: 751-757.

65. Jurban A, Van De Graaff WB, Tobin MJ. Variability of patient-ventilator interaction with pressure support ventilation in patients with chronic obstructive pulmonary disease. Am J Respir Crit Care Med 1995; 152: 129-136.

66. O'Donnell D, Anthonisen NR, Sanii R, Younes M. Effect of dynamic airway compression on breathing pattern and respiratory sensation in severe COPD. Am Rev Respir Dis 1987; 135: 912-919.

67. Marcy TW, Marini JJ. Respiratory distress in the ventilated patient. Clin Chest Med 1994; 15: 55-73. 